\title{
Evaluating Economic Benefits of Water Diversion Project for Environment Improvement: A Case Study
}

\author{
Xundi DIAO ${ }^{1}$, Saixing ZENG ${ }^{1}$, Haoyun WU $^{2}$ \\ ${ }^{1}$ Antai School of Management, Shanghai Jiaotong University, Shanghai, China \\ ${ }^{2}$ School of Management, Tongji University, Shanghai, China \\ Email:diaoxundi@163.com \\ Received November 29, 2008; revised January 24, 2009; accepted February 12, 2009
}

\begin{abstract}
The research in this paper was based on the project of water diversion from the Yangtze River to the Taihu Lake which significantly improves water environment of the lake and brings obvious economic benefits for surrounding areas. An analytical framework is developed on evaluating benefits of water supply to Huzhou city from project of water diversion from Yangtze River to Taihu Lake, including: (1) the value-added of water supply on the project are divided into four parts according to the characteristics of Hangzhou- Jiaxing-Huzhou Plain area. (2) The utilization ratio of water diversion is defined based on the features of water resources. (3) The water supply effects on industries and residents' living are explored using partition coefficient method in Huzhou city. Grey relation technique is used to examine the relationship between water use and industrial development in Huzhou, which aims to clarify the rationality of partition coefficient method. The results indicate that benefit of water diversion from Yangtze River to Taihu Lake to tertiary industry of Huzhou city is the highest, while that of industry is the lowest.
\end{abstract}

Keywords: Water Environment, Water Diversion, Economic Benefit, Grey Correlation

\section{Introduction}

With rapid economic development and great population increase, contradictions among population, resources, environment and development have become a serious challenge. There are extensive reports on this problem based on developed countries such as American, Britain, Holand and Australia. Gardiner advocated the integrated management of river basin aiming to realize river basin's sustainable development [1,2]. National Rivers Authority (NRA) (1995) in Britain published Thames Basin Agenda 21 and Sustainable Development Strategy [3]. The United States Environment Protection Agency (EPA) has addressed importance to governing river basin since 1990 .

Since China's reform and opening policy in 1978, Taihu Lake Basin area has changed rapidly. According to the statistics supplied by Taihu Lake Basin Authority, Ministry of water Resources, P. R. China, in 2005, the area created GDP of $13 \%$ with its population of $3.2 \%$ and area of less than $0.4 \%$ in China; and in 2006, it created GDP of $11.1 \%$ with its population of $2.8 \%$ and area of less than $0.4 \%$ in China. However, poor water condi- tions have been a factor restricting socio-economic development and causing environmental deterioration. Traditional water supply cannot help to provide more water to meet growing demands [4]. Water is often imported through inter-basin water transfers across national, regional and local boundaries to meet increasing off-stream demands in agriculture, industry, hydropower, and household sectors for economic and social development [5]. The project of water diversion from Yangtze River to Taihu Lake, to some extent, covers the shortage of water.

Diverting Yangtze River water into Taihu Lake is by the Wang Yu River project to introduce water from Yangtze River into Taihu Lake and its ambient plain river area, then by the Taipu River project to supply water for downstream area (e.g., Hangzhou-Jiaxing-Huzhou Plain area) (see Figure 1). It officially started in 2002. By the end of 2006, it has transferred 7.42 billion $\mathrm{m}^{3}$ water from Yangtze River into Taihu Lake Basin, of which 3.24 billion $\mathrm{m}^{3}$ into Taihu Lake; at the same time it has supplied 9.02 billion $\mathrm{m}^{3}$ for downstream area by way of Taipu brake, of which nearly half of water for Hangzhou-Jiaxing-Huzhou area [6]. 


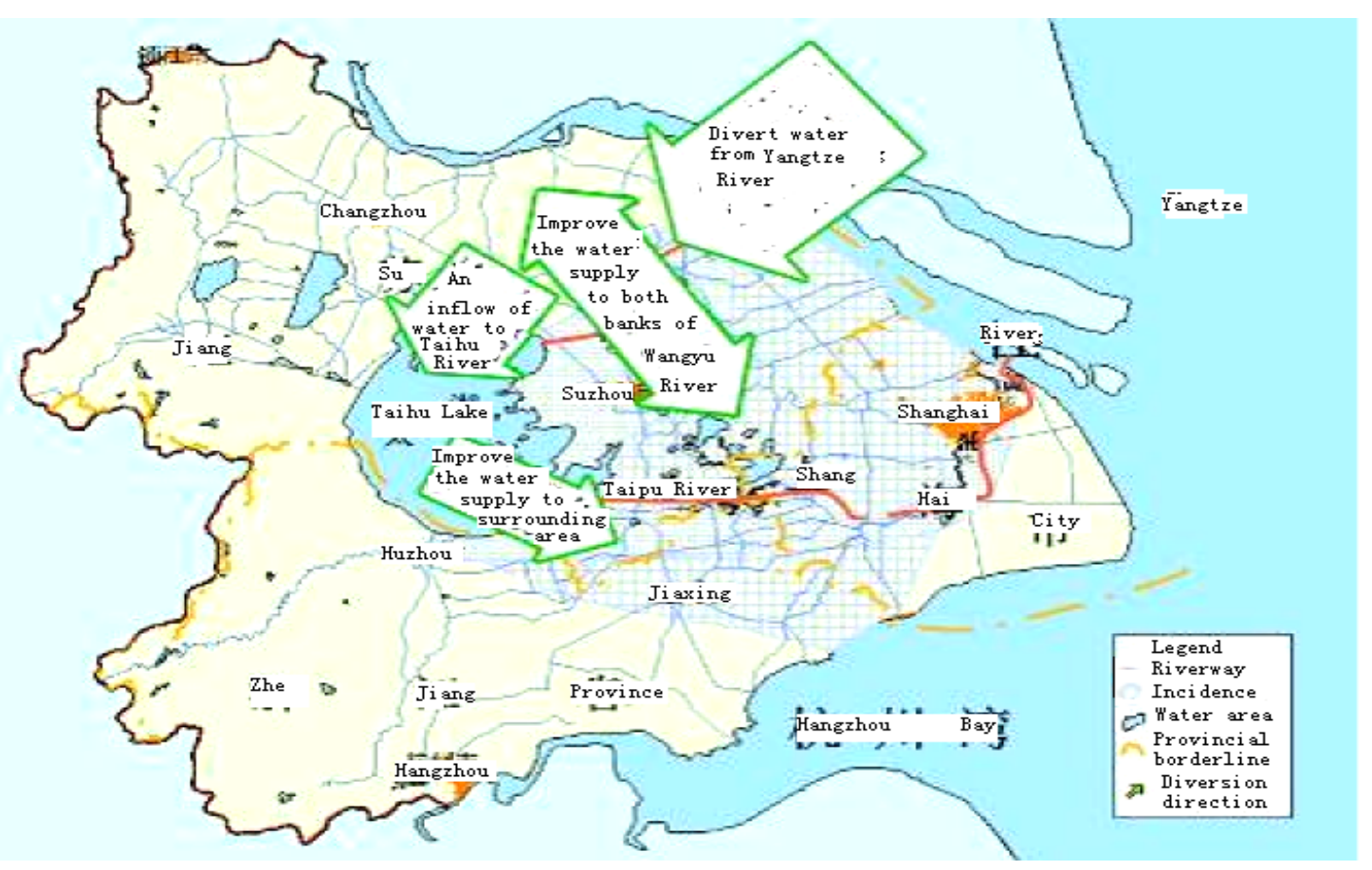

Figure 1. Sketch map of water diversion from Yangtze River to Taihu Lake.

Huzhou city, a city of Zhejiang province and near south of Taihu Lake, is located in the mid-upriver of Taihu basin. Because of its especial geographic position, Huzhou city is always one of the important cities which greatly benefit from the project of water diversion from Yangtze River to Taihu Lake. In the area, water from Taihu Lake is introduced by using two channels. One is that water from Taihu Lake supplies water for basin lower reaches by way of Taipu River. While water from Taipu River directly enters Hangzhou-Jiaxing-Huzhou Plain area by way of Jing-Hang Grand Canal, You Pond, Da Zheng Pond and Wu Zi Pond. The other is that water from Taihu Lake supplies water for east parts of Hangzhou-Jiaxing-Huzhou Plain area by way of river diversion brakes of East Tiao Xi and Lou Harbor entrances of Taihu Lake.

Based on the practical measure and analysis for years by Taihu Lake Basin Authority, Ministry of water Resources, P. R. China, the results show that in HangzhouJiaxing-Huzhou Plain area the range of influence from water flow are mainly east and west plains of Hangzhou-Jiaxing-Huzhou area with the area of about 3 thousand $\mathrm{m}^{2}$, of which Huzhou city is the core beneficial area.

The paper aims in providing an analytical framework for evaluating benefits of water diversion projects.

\section{Model Development}

In order to analyze the benefits of supply water to the intake area, the method of partition coefficient was employed. That is, the benefits of supply water to the intake area can be computed in creating value-added process according to contribution rate of water to primary industry, industry (included in secondary industry), tertiary industry and residential living.

The benefits of supply water for primary industry, industry, tertiary industry and residential living can be calculated as (1):

$$
B_{s}=V_{s} \cdot\left(f_{s} \cdot q_{s} \cdot k_{s}\right)
$$

where $s$ represents the economic sector of interest (e.g., primary industry), $B$ benefit of supply water, $V$ benefit of each cubic water, $f$ partition coefficient, $q$ value-added of water supply and $k$ utilization ratio of water diversion.

Individually, for primary industry, industry, tertiary industry, $V$ can be calculated as (2):

$$
V=I / W
$$

However, for residential living, $V$ has the form of (3):

$$
V=r \cdot e / p
$$

In (2) and (3), all the variables are explained as follows.

$I$-value-added of each industry

$W$-total volume of water use

$r$-disposable income of residents

$e$-Engel's coefficient

$p$-per capita water consumption of every year

Adopting the method of partition coefficient to calculate economic benefits of water supply is one of the methods according to the calculation norm of water resources economics. The method can show the correlation 
among benefits, inputs and outputs. It has been proved suitable in theory and convenient in practice. The key to use the method is how to define the partition coefficient of benefits of water supply. When partition coefficient is appropriately chosen, the benefits of water supply can be concordant with practical results.

\section{Description of Variables}

In order to calculate the benefits of water supply $B$ on the project of water diversion from Yangtze River to Taihu Lake, the eight variables, that is, value-added of water supply $q$, value-added of each industry $I$, total volume of water use $W$, partition coefficient $f$, disposable income of residents $r$, Engel's coefficient $e$, per capita water consumption of every year $p$ and utilization ratio of water diversion $k$, must be given.

\subsection{Value-Added of Water Supply}

In Hangzhou-Jiaxing-Huzhou Plain area, there are multiple rivers and complex river nets with cross-piercing at the bottom as a big container. The water by diversion from Yangtze River to Taihu Lake can freely flow in the area. Thus allocating the value-added of water supply according to water use ratio can reflect the practical water utilization.

The lines of water diversion in the project of water diversion from Yangtze River to Taihu Lake are mainly two: one is supplying water to Hangzhou-Jiaxing-Huzhou Plain area by passing through the Lou harbors of the circle Taihu Lake; another is by passing through the Taipu River. The value-added of water supply are showed in Table 1. By the end of 2005, the total value-added of water supply to Hangzhou-Jiaxing-Huzhou Plain area has been up to 3.926 billion $\mathrm{m}^{3}$ by the project.

Based on analyzing the water utilization of HangzhouJiaxing-Huzhou Plain area in 2000, the value-added of water supply to every industry and residential living of Huzhou on the project of water diversion from Yangtze River to Taihu Lake were calculated respectively, as listed in Table 2.

Table 1. Value-added volumes of water supply to HangzhouJiaxing-Huzhou plain area on project of water diversion from Yangtze river to Taihu Lake, 2002-2005 Unit: $10^{8} \mathrm{~m}^{3}$.

\begin{tabular}{cccc}
\hline Year & Taipu River & Circle Taihu Lake & $\begin{array}{c}\text { Total Value-added of } \\
\text { Water Supply }\end{array}$ \\
\hline $\mathbf{2 0 0 2}$ & 2.65 & 1.06 & 3.71 \\
$\mathbf{2 0 0 3}$ & 6.5 & 5.90 & 12.40 \\
$\mathbf{2 0 0 4}$ & 2.66 & 6.61 & 9.27 \\
$\mathbf{2 0 0 5}$ & 4.06 & 9.82 & 13.88 \\
Total & 15.87 & 23.39 & 39.26 \\
\hline
\end{tabular}

Source: Taihu Lake Basin Authority, Ministry of Water Resources, P. R. China.
From Table 2, we can see that the value-added volume of water supply to Huzhou city on the project is steadily increasing. However, in 2003 the value-added of water supply added to 0.131 hundred million $\mathrm{m}^{3}$ from the value-added of 0.039 hundred million $\mathrm{m}^{3}$ in 2002 because the year of 2003 is especially on shortage of water. Thus the water height in Huzhou city in 2003 is above the normal water level so as to keep the water quality stable and alleviate water demand in Huzhou city.

\subsection{Utilization Ratio of Water Diversion}

The total volume of value-added of water supply by the project of water diversion from Yangtze River to Taihu Lake is not possible to be completely used, of which they are discharged without being used. Thus when the direct economic benefits of water diversion are calculated, the parts of water transmission losses should not be computed. In the paper, the utilization ration of water diversion $k$ is defined as (4):

$$
k=q_{0} / q
$$

where $q_{0}$ represents the practical use volume of water diversion and $q$ describes the total volume of water diversion. The value of $k$ is decided by the shortage degree and the use capability of water resources in the researched area. According to the total planning of water resources protection and use capability in Zhejiang province, the utilization ration of water diversion is approximately 0.6 in recent years. Thus the utilization ratio of water diversion in Huzhou city is chosen as 0.6.

\subsection{Partition Coefficient}

The option of the partition coefficient of benefits of water supply is quite important. The benefits of water supply are not concordant with practical results until the partition coefficient is appropriately chosen.

Table 2. Value-added volumes of water supply to three industries and residential living of Huzhou city on project of water diversion from Yangtze River to Taihu Lake, 2002-2005

Unit: $10^{8} \mathrm{~m}^{3}$.

\begin{tabular}{cccccc}
\hline Year & $\begin{array}{c}\text { Total } \\
\text { Value-add } \\
\text { ed of } \\
\text { Water } \\
\text { Supply }\end{array}$ & $\begin{array}{c}\text { Value-adde } \\
\text { d of Water } \\
\text { Supply to } \\
\text { Primary } \\
\text { Industry }\end{array}$ & $\begin{array}{c}\text { Value-adde } \\
\text { d of Water } \\
\text { Supply to } \\
\text { Industry }\end{array}$ & $\begin{array}{c}\text { Value-adde Value-added } \\
\text { d of Water } \\
\text { Supply to } \\
\text { Tertiary } \\
\text { Industry }\end{array}$ & $\begin{array}{c}\text { of Water } \\
\text { Supply to } \\
\text { Residential } \\
\text { Living }\end{array}$ \\
\hline $\mathbf{2 0 0 2}$ & 0.362 & 0.176 & 0.072 & 0.014 & 0.039 \\
$\mathbf{2 0 0 3}$ & 1.210 & 0.588 & 0.240 & 0.046 & 0.131 \\
$\mathbf{2 0 0 4}$ & 0.905 & 0.439 & 0.180 & 0.034 & 0.098 \\
\hline $\mathbf{2 0 0 5}$ & 1.355 & 0.658 & 0.269 & 0.051 & 0.147 \\
\hline
\end{tabular}


1) Partition coefficient of primary industry

Generally, the increasing of production of farm crop results from the synthetical effects of water, fertilizer, seed, soil improvement and technical measures in primary industry (e.g. prevention from disease and insect pest). Thus, allocating the total value-added of production should be scientifically transacted. According to the computation results of benefits of irrigation for many years in Jiangsu, Zhejiang and Shanghai, the average partition coefficients of primary industry in Taihu Lake are individually shown as follows: it is 0.4 in level water year, 0.53 in low water year or slightly low water year. Thus, according to the situation of rain water in Huzhou city in 2002-2005, we can define the average partition coefficients of primary industry (Table 3).

2) Partition coefficient of industry

By the use of the data in Huzhou Statistical Yearbook (1989-2005) [7], an industrial production function can be showed as (5). The equation can be gained by the regression analysis with total production of industry $Y$ as dependent variable, and fixed assets $K$, populations of labour force $L$ and total volume of water use of industry $W$ as independent variables.

$$
Y=0.997 K^{0.493} L^{0.534} W^{0.242}
$$

In (5), it indicates that the contribution coefficient of water to industry is about 0.2 . That is to say that the total production will increase by $0.2 \%$ with the increase of water use of $1 \%$. In recent years, the average value-added rate of industry is near 0.25 in Huzhou city. It shows that the total production of industry will increase by $0.05 \%$ with the increase of water use of $1 \%$ in Huzhou city. Thus, the partition coefficient of industry in Huzhou city is about 0.05 .

3) Other partition coefficient

The contribution rate of water to restore labour force is defined as the partition coefficient of tertiary industry. The value is 0.3 according to Chen [8]. The partition coefficient of residential living is calculated by the contribution rate of all kinds of the living materials to restore labour force. According the viewpoint of the Chen [8], the value is thought as 0.3 in this paper.

\subsection{Other Variables}

The value-added of each industry $I$ and disposable income of residents $r$ can be attained from Huzhou

Table 3. Average partition coefficients of primary industry in 2002-2005.

\begin{tabular}{ccccc}
\hline Year & $\mathbf{2 0 0 2}$ & $\mathbf{2 0 0 3}$ & $\mathbf{2 0 0 4}$ & $\mathbf{2 0 0 5}$ \\
\hline Rain Water & $\begin{array}{c}\text { Lever } \\
\text { water }\end{array}$ & $\begin{array}{c}\text { Low } \\
\text { water }\end{array}$ & $\begin{array}{c}\text { Slightly } \\
\text { low water }\end{array}$ & $\begin{array}{c}\text { Slightly } \\
\text { low water }\end{array}$ \\
$\begin{array}{c}\text { Average Parti- } \\
\text { tion Coefficient }\end{array}$ & 0.4 & 0.53 & 0.53 & 0.53 \\
\hline
\end{tabular}

Statistical Yearbook (2002-2005) [7,9-11]. Total volume of water use $W$ can be obtained from Huzhou Water Resources Bulletin. Engel's coefficient $e$ can be calculated by (5). Per capita water consumption of every year $p$ can be demonstrated by (6).

$$
\begin{gathered}
e=e_{1} / e_{2} \\
p=W / P o p
\end{gathered}
$$

where $e_{1}$ describes the food expenditure, $e_{2}$ shows the total expenditure and Pop defines the population in cities and towns. The value of the three variables can be obtained from Huzhou Statistical Years (2002-2005) [7, 9-11].

\section{Results}

Using (1) and (2), the economic benefits of water supply to the three industries of Huzhou city on the project of water diversion from Yangtze River to Taihu Lake were calculated in the years of 2002-2005, as listed in Table 4.

By (1) and (3), the economic benefits of water supply to the resident living of Huzhou city on the project of water diversion from Yangtze River to Taihu Lake were calculated in the years of 2002-2005, as listed in Table 5.

In Table 4 and Table 5, it indicates that in the years of 2002-2005, economic benefits of water supply for primary industry, industry (included in secondary industry), tertiary industry and the residential living of Huzhou city on the project of water diversion from Yangtze River to Taihu Lake are respectively 1.726 hundred million Yuan, 1.309 hundred million Yuan, 12 hundred million Yuan and 0.415 hundred million Yuan. Among them, economic benefit of water supply for tertiary industry is the highest. And the next is primary industry.

\section{Evaluating of Economic Benefits of Water Diversion}

Although using the method of partition coefficient to calculate economic benefits of water supply is useful, there are some limitations. For example, more investment in the project of water supply, more economic benefits which is unreasonable in practice. Thus, in order to validate the rationality of adopting the method applied in the Huzhou area, the grey relation analysis method is chosen.

Compared with traditional statistical methods which require more data and time, the grey relation analysis (GRA) only needs minimal data to get reasonable and good results. The technique of grey relation analysis has been applied in many fields. For example, Morita et al. [12] applied GRA to examine the annual load demand of the power system in Japan, and drew a conclusion that the grey system for the long-term load forecasting problem 
Table 4. Economic benefits of water supply to three industries of Huzhou city on project of water diversion from Yangtze River to Taihu Lake, 2002-2005 Unit: $10^{8}$ Yuan $^{3}$.

\begin{tabular}{cccccc}
\hline \multicolumn{1}{c}{ Year } & $\mathbf{2 0 0 2}$ & $\mathbf{2 0 0 3}$ & $\mathbf{2 0 0 4}$ & $\mathbf{2 0 0 5}$ & Total \\
\hline $\begin{array}{l}\text { Primary Industry } \\
\text { Industry (belong to }\end{array}$ & 0.100 & 0.492 & 0.493 & 0.641 & 1.726 \\
$\begin{array}{l}\text { secondary industry) } \\
\text { Tertiary Industry }\end{array}$ & 0.115 & 0.389 & 0.303 & 0.502 & 1.309 \\
\hline
\end{tabular}

Table 5. Economic benefits of water supply to residential living of Huzhou city on project of water diversion from Yangtze River to Taihu Lake, 2002-2005 Unit: $10^{8}$ Yuan $^{3}$.

\begin{tabular}{cccccc}
\hline Year & 2002 & 2003 & 2004 & 2005 & Total \\
Residential Living & 0.039 & 0.131 & 0.098 & 0.147 & 0.415 \\
\hline
\end{tabular}

Table 6. Statistical results on total volume of water use and structure of gross domestic product in Huzhou city.

\begin{tabular}{|c|c|c|c|c|}
\hline Year & $\begin{array}{c}\text { Total volume } \\
\text { of water } \\
\text { (billion } \mathbf{m}^{3} \text { ) }\end{array}$ & $\begin{array}{l}\text { Value-added } \\
\text { of Primary } \\
\text { Industry (\%) }\end{array}$ & $\begin{array}{l}\text { Value-adde } \\
\text { d of Indus- } \\
\text { try (\%) }\end{array}$ & $\begin{array}{c}\text { Value-added } \\
\text { of Tertiary } \\
\text { Industry (\%) }\end{array}$ \\
\hline 2002 & 1.804 & 12.2 & 46.6 & 34.2 \\
\hline 2003 & 1.764 & 11.3 & 46.7 & 35.4 \\
\hline 2004 & 1.841 & 11 & 47.8 & 34.2 \\
\hline 2005 & 1.776 & 9.8 & 48.8 & 35.25 \\
\hline
\end{tabular}

Source: 2005 Huzhou Statistical Yearbook, P. R. China [7] and Huzhou Water Resources Bulletin, P. R. China (2002-2005) [14].

Table 7. Results of grey relation analysis method.

\begin{tabular}{cccc}
\hline \multirow{2}{*}{ Item } & \multicolumn{3}{c}{$\begin{array}{c}\text { Grey Relation Degree of Structure of Gross } \\
\text { Domestic Product }\end{array}$} \\
\cline { 2 - 4 } & Primary Industry & Industry & Tertiary Industry \\
\hline $\begin{array}{c}\text { Grey rela- } \\
\text { tion degree } \\
\text { Weight }\end{array}$ & 0.7372 & 0.5697 & 0.8068 \\
\hline
\end{tabular}

had a higher accuracy than the linear single regression model. Lin et al. [13] used GRA to analyse the productivity, aggregate energy consumption, and the use of fuel mix in relation to $\mathrm{CO}_{2}$ emission changes and thus the suggestions are given.

According to the grey relation analysis method, the total volume of water use were considered as main element sequence, and the structure of gross domestic product was thought as sub-element sequences (see Table 6). The computational results are listed in Table 7.

From Table 7, the grey relation degree of value-added of tertiary industry is the highest, reaching the value of 0.8068 , while that of industry is the lowest with the value of 0.5697 . Thus, adding the water supply can greatly improve the value-added of tertiary industry.

\section{Conclusions}

The paper has developed an analytical research framework on benefits of water supply to Huzhou city on the project of water diversion from Yangtze River to Taihu Lake. The result is perfectly coincident with that of the grey relation degree analysis method. It also showed that the project of water diversion from Yangtze River to Taihu Lake plays an important role in improving economic benefits to Huzhou city. It also proves significant and necessary to continuously implement water diversion from Yangtze River to Taihu Lake.

However, in the paper, only direct economic benefits of water supply to Huzhou city on the project of water diversion from Yangtze River to Taihu Lake were calculated by analyzing the value-added of water supply. It is insufficient in researching ecological and social benefits, such as zoology, environment, health and physiology etc., with water improvement and water flow changes resulting from the increase of value-added of water supply. The future research will focus on the ecological and social benefits of the project.

\section{Acknowledgments}

The authors gratefully acknowledge Mr. J. J. Yan, Miss X. J. Hu and Mr. L. Sun in Antai School of Management, Shanghai Jiaotong University, Shanghai, China, for their assistance in collecting data and helpful suggestions in the research. This study is supported by Research Center on Metropolitan Regions of China and Shanghai Philosophy and Social Science Foundation (2008SBF002).

\section{References}

[1] J. L. Gardiner, P. J. Edwards, and J. H. Ball, "Urban waterside regeneration: Context and sustainability," in: White, K. N., Bellinger, E. G., Saul, A. J., Symes, M. \& Hendry, K. (Eds) Urban Waterside Regeneration (London, Ellis Horwood), 1993.

[2] J. L. Gardiner, "Sustainable development for river catchments," Journal of the Institution of Water and Environmental Management, Vol. 8, pp. 308-319, 1994.

[3] National Rivers Authority, "Thames 21-A planning perspective and a sustainable strategy for the thames region,” Reading, National Rivers Authority, 1995.

[4] Y. Zhou and Richard S. J. Tol, "Implications of desalination for water resources in China-an economic perspective,” Desalination, Vol. 164, pp. 225-240, 2004.

[5] M. Matete and R. Hassan, "Integrated ecological economics accounting approach to evaluation of inter-basin water transfers: An application to the Lesotho Highlands Water Project," Ecological Economics, Vol. 60, pp. 246-259, 2006. 
[6] "Report on implementing the project of water transfer from Yangtze River to Taihu Lake,” Taihu Lake Basin Authority, Ministry of Water Resources, P. R. China, pp. 385-403, 2005.

[7] “2005 Huzhou Statistical Yearbook,” China Statistic Press, 2006.

[8] X. R. Chen and X. K. Liu, "Rational volume of ecological water consumption and its calculation model II: Application,” Advances in Science and Technology of Water Resources, Vol. 26(6), pp. 1-5, 2006.

[9] “2002 Huzhou Statistical Yearbook,” China Statistic Press, 2003.

[10] “2003 Huzhou Statistical Yearbook,” China Statistic
Press, 2004.

[11] “2004 Huzhou Statistical Yearbook,” China Statistic Press, 2005.

[12] H. Morita, T. Kase, Y. Tamura, and S. Lwamoto, "Interval prediction of annual maximum demand using grey dynamic model," Electrical Power and Energy System, Vol. 18, pp. 409-413, 1996.

[13] S. J. Lin, I. J. Lu, and Charles Lewis, "Grey relation performance correlations among economics, energy use and carbon dioxide emission in Taiwan,” Energy Policy, Vol. 35, pp. 1948-1955, 2007.

[14] "Huzhou water resources bulletin,” The Agency of Water Resources of Huzhou City, 2002-2005. 